\title{
Clinical outcomes of ultrathin biodegradable polymer-coated sirolimus-eluting stents in an all-comer population: One-year results from the T-FLEX registry including high-risk subgroups
}

\author{
Ramesh Babu Pothineni (D), Vikrant Vijan1 (D), Anil Potdar² (D), Manohar K. Inamdar³ (D), Abhijit Pathak ${ }^{4}$ (D), \\ Sai Sudhakar Mantravadi ${ }^{5}$ (D), Prakash Ajmera ${ }^{6}$ (i) \\ Department of Cardiology, Ramesh Hospitals; Andhra Pradesh-India \\ ${ }^{1}$ Department of Cardiology, Vijan Hospital and Research Centre; Maharashtra-India \\ ${ }^{2}$ Department of Cardiology, Parisoha Foundation Pvt. Ltd.; Mumbai-India \\ ${ }^{3}$ Department of Cardiology, Ashwini Hospital; Maharashtra-India \\ ${ }^{4}$ Department of Cardiology, Swasthya Hospital and Medical Research Center; Maharashtra-India \\ ${ }^{5}$ Department of Cardiology, Gleneagles Global Hospital; Telangana-India \\ ${ }^{6}$ Department of Cardiology, Malla Reddy Narayana Multispeciality Hospital; Telangana-India
}

\section{ABSTRACT}

Objective: T-Flex registry was designed to investigate the safety and clinical performance of the ultrathin (60 $\mu \mathrm{m})$ strut biodegradable polymercoated sirolimus-eluting stent (SES) with a unique long dual Z (LDZ) link design on a cobalt-chromium stent platform (Sahajanand Medical Technologies Pvt. Ltd., Surat, India) in a real-world all-comer population including high-risk subgroups.

Methods: This was an observational, multicenter, single-arm, and investigator-initiated retrospective registry. A total of 1,203 patients treated with an ultrathin biodegradable polymer-coated SES, irrespective of lesion complexity, comorbidities, and acute presentation were analyzed from May 2016 to January 2017. The primary endpoint was the one-year incidence of target lesion failure (TLF), a composite of cardiac death, target-vessel myocardial infarction (TV-MI), and clinically-indicated target lesion revascularization (CI-TLR). Stent thrombosis was assessed as an additional safety endpoint.

Results: At the one-year follow-up, TLF was observed in 3.8\% [95\% confidence interval (CI) 2.9-5.1] patients, composed of 0.6\% (95\% Cl: 0.3-1.3) cardiac death, 1.3\% (95\% Cl: 0.8-2.2) TV-MI, and 1.9\% (95\% Cl: 1.3-2.9) Cl-TLR. In the high-risk subgroups, TLF at one-year was 6.8\% (95\% Cl: 4.6-9.8) in patients with diabetes, $5.2 \%(95 \% \mathrm{Cl}$ : $3.4-8)$ in patients with small-vessel disease, $6.1 \%(95 \% \mathrm{Cl}$ : $3.9-9.6)$ in patients with ST-elevation myocardial infarction, and 4.5\% (95\% Cl: 2.4-8.3) in patients with total occlusion. During follow-up, stent thrombosis was reported in $0.8 \%$ (95\% Cl: 0.4-1.5) patients in the overall population.

Conclusion: Low event rates of TLF and stent thrombosis at one-year follow-up indicate that this ultrathin biodegradable polymer-coated SES has encouraging safety and clinical performance in real-world all-comer populations as well as in high-risk subgroups.

Keywords: biodegradable polymer, percutaneous coronary intervention, sirolimus-eluting stent, stent thrombosis, target lesion failure, ultrathin strut

Cite this article as: Pothineni RB, VijanV, Potdar A, Inamdar MK, Pathak A, Mantravadi SS, et al. Clinical outcomes of ultrathin biodegradable polymer-coated sirolimus-eluting stents in an all-comer population: One-year results from the T-FLEX registry including high-risk subgroups. Anatol J Cardiol 2021; 25: 706-15.

\section{Introduction}

Since its inception, percutaneous coronary intervention for the treatment of coronary artery disease has undergone a continuous transition to achieve an optimal stent design. The breakthrough discovery of drug-eluting stents (DES) significantly reduced neointimal proliferation and high rates of restenosis compared with those of bare-metal stents (BMS). However, it raised long-term safety issues related to late and very late stent thrombosis, attributable to chronic inflamma- 


\section{HIGHLIGHTS}

- Since its inception, percutaneous coronary intervention for the treatment of coronary artery disease has undergone a continuous transition to achieve an optimal stent design. New stent engineering aims to improve means of deliverability and safety profile.

- Thinner stent struts are associated with lowered crimp profile, increased flexibility, improved stent deliverability, and trackability in the severely calcified and tortuous path of complex coronary lesions, and improved clinical performance.

- The T-Flex registry yielded low one-year target lesion failure and stent thrombosis rates. These results clearly depict excellent safety and clinical performance of this ultrathin biodegradable polymer-coated sirolimus-eluting stent in real-world all-comer populations as well as in high-risk subgroups with coronary artery disease.

tion or delayed hypersensitivity reaction caused by the persistent presence of polymers in DES (1-3). Subsequent innovations in DES components have been made to overcome the limitations of prior generation DES (4). Accordingly, the newer generation DES have evolved from durable polymers to biodegradable polymers and from thick strut to ultrathin strut with newer anti-proliferative agents to develop a stent with maximal safety and efficacy profiles and improved performance (5-7).

The major clinical advantage of a biodegradable polymer is that it undergoes degradation after the drug has been eluted, thereby reducing local inflammatory reaction and irritation leaving only a metal stent in adhesion with neointima and endothelium. Similarly, thinner stent struts have been developed to enhance the biocompatibility, which resulted in lower restenosis rates after stent placement $(8,9)$. Moreover, thinner struts are also associated with lowered crimp profile, increased flexibility, improved stent deliverability, and trackability in the severely calcified and tortuous path of complex coronary lesions, and improved clinical performance $(10,11)$. Although sirolimus-eluting cobalt-chromium stents have demonstrated excellent longterm safety and efficacy outcomes in a wide range of studies (12-21), new stent engineering is aimed at improving its means of deliverability and safety profile. The ultrathin $(60 \mu \mathrm{m})$ biodegradable polymer-coated sirolimus-eluting stent (SES) (Sahajanand Medical Technologies Pvt. Ltd., Surat, India) is one such latest-generation coronary stent with unique "long dual Z (LDZ) link" on a cobalt-chromium stent platform. The T-Flex registry presents one-year safety and clinical performance outcomes for this ultrathin SES in patients with coronary artery disease in a real-world all-comer population as well as high-risk subgroups, such as patients with diabetes mellitus, small coronary vessels $(\leq 2.5 \mathrm{~mm})$, ST-elevation myocardial infarction (STEMI), and total occlusions.

\section{Methods}

\section{Study design and patient population}

T-Flex registry was an observational, multicenter, single-arm, investigator-initiated retrospective registry conducted at seven tertiary-care centers in India. The registry population comprised real-world all-comer patients with coronary artery disease, who were treated with at least one ultrathin biodegradable polymercoated SES designed with a LDZ link, between May 2016 and January 2017. As the registry was aimed at studying a real-world and all-comer population, no specific clinical or angiographic exclusion criteria were defined; and all consecutive patients satisfying the inclusion criteria were examined, irrespective of lesion complexity, comorbidities, and acute presentation. The study protocol was approved by the Institutional Ethics Committee. The registry, design, and procedures conformed to the principles of Good Clinical Practice (22) and the Declaration of Helsinki (23). Signed informed consent for data collection and its analysis for research purposes was obtained from each patient.

\section{Description of the study stent}

The ultrathin biodegradable polymer-coated SES has the latest-generation Tetrinium L-605 cobalt-chromium alloy with a strut thickness of $60 \mu \mathrm{m}$ as its stent platform (Sahajanand Medical Technologies Pvt. Ltd., Surat, India). The multi-layer coating on the conformal surface of the SES contains $1.4 \mu \mathrm{g} /$ $\mathrm{mm}^{2}$ of sirolimus drug blended with a biodegradable polymeric matrix comprising a combination of hydrophilic and hydrophobic polymers, containing poly (L-lactide) (PLLA), poly (L-lactide-cocaprolactone) (PLCL), and polyvinylpyrrolidone (PVP). These polymers provide elastomeric property to the coating to aid with the metal expansion mechanism and control the drug elution from the stent coating. SES is designed to release the drug at a sustained rate. Nearly $80 \%$ of the drug is released within four weeks in biological media. The remaining drug is programmed to be released at a slow rate in approximately three months. Figure 1 represents the in vitro percentage cumulative drug release profile of SES. After releasing the drug, biodegradable polymers undergo hydrolysis and then gradually degrade into biologically

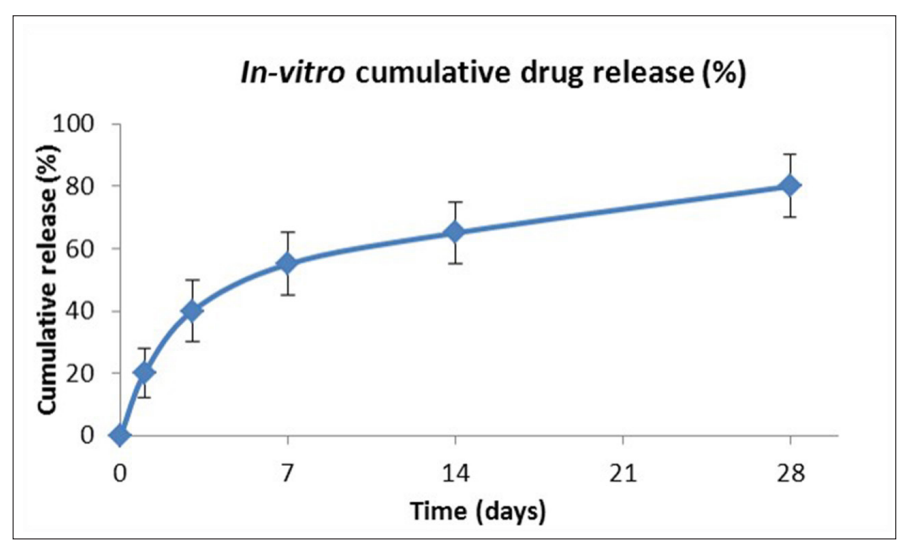

Figure 1. In vitro drug release profile of the ultrathin biodegradable polymer-coated sirolimus-eluting stent 


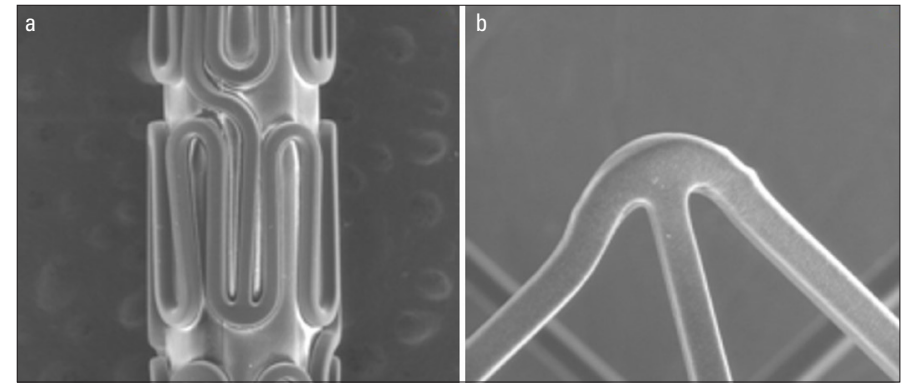

Figure 2. Scanning electron microscopy images of (a) crimped and (b) expanded ultrathin biodegradable polymer-coated sirolimus-eluting stents

acceptable molecules that are metabolized and removed from the body via normal metabolic pathways. The average coating thickness of SES is between 4 and $6 \mu \mathrm{m}$. The unique coating matrix offers excellent coating adhesion with a stent surface. The multi-layer coating technology offers precise control over drug release to accommodate arterial drug requirements post stent implantation. Further, the unique blend of biodegradable polymers in each layer aids in achieving controlled drug release and offers unmatched coating integrity. Moreover, the drug-free top layer comprised hydrophilic polymers with antioxidants tends to improve product shelf life and protect coating layers during implantation. The scanning electron microscopy images of sterile crimped stents and expanded stents are displayed in Figure 2, revealing a smooth and uniform coating surface without any coating anomalies and defects such as webbing, bridging, and strut-to-strut contact, even after expansion of the stent. During the study period, the SES was made available in lengths of $8,12,16,20,24,28,32,36,40,44$, and $48 \mathrm{~mm}$ and diameters of $2.00,2.25,2.50,2.75,3.00,3.50,4.00$, and $4.50 \mathrm{~mm}$.

\section{Coronary intervention procedure and adjunctive medications}

Coronary interventional procedures and adjuvant medications were performed per the standard guidelines (24). Dual antiplatelet therapy (DAPT) including a loading dose of aspirin $(300 \mathrm{mg})$ and clopidogrel $(600 \mathrm{mg})$ or prasugrel $(60 \mathrm{mg}$ ) or ticagrelor $(180 \mathrm{mg})$ was given to each patient. Procedural anticoagulation was achieved either with heparin or bivalirudin. However, administration of intra-procedural glycoprotein Ilb/IIla inhibitor was at the investigator's discretion. All the patients were advised to maintain DAPT (aspirin 75-300 mg daily indefinitely and clopidogrel $75 \mathrm{mg}$ daily or prasugrel $10 \mathrm{mg}$ daily or ticagrelor $90 \mathrm{mg}$ twice daily for at least 12 months) after the procedure.

\section{Data collection and patient follow-up}

All data including demographic information, cardiovascular history, comorbidities, clinical presentation, lesions, and procedural characteristics were obtained from the hospital records of each study center. Follow-up data were obtained retrospectively either by extraction from existing databases in a consecutive fashion where index and follow-up data existed or were obtained by telephonic contact one year after stent implantation. During these follow-ups, information about patients' clinical conditions and the occurrence of any adverse events or hospitalizations were collected. Whenever an event occurred, attempts were made to obtain copies of medical records or any other relevant documents to adjudicate the event. Long-term follow-up will be done for up to three years.

\section{Study endpoints}

The primary endpoint of the T-Flex registry was the incidence of target lesion failure (TLF), which was defined as a composite endpoint of cardiac death, target-vessel myocardial infarction (TV-MI), and clinically-indicated target lesion revascularization (CI-TLR) by percutaneous or surgical methods after one year. Secondary endpoints included device success, procedural success, and incidence of all separate components of the primary endpoint. At each follow-up, events of stent thrombosis were evaluated as an additional safety endpoint, which was classified into definite, probable, and possible stent thrombosis on the basis of criteria defined by the Academic Research Consortium (ARC) (24).

\section{Study definitions}

For this registry, any death due to a cardiac cause such as myocardial infarction (MI), low-output failure, lethal arrhythmia or unwitnessed death, death of unknown reason, and all procedurerelated deaths linked to concomitant treatment was stated as cardiac death, whereby non-cardiac death included any death where a non-cardiac cause was well established. MI was defined according to the third universal definition (25). TV-MI was defined as an MI with evidence of myocardial necrosis in the vascular territory of the previously treated target vessel. CI-TLR was described as any revascularization procedure in the target lesion with stenosis $>50 \%$ in association with clinical or functional ischemia (positive functional study, electrocardiographic changes, or ischemic symptoms), or stenosis $>70 \%$ in the absence of clinical or functional ischemia. Device success was defined as successful delivery, deployment, and withdrawal of the assigned device at the intended target lesion with a final in-stent residual stenosis of $<30 \%$ by visual estimation. Procedural success was defined as device success of all intended target lesions without the occurrence of TLF during the index procedure hospital stay.

\section{Statistical analysis}

All data were analyzed with the IBM Statistical Package for Social Sciences for Windows, version 20.0. (Armonk, NY: IBM Corp., USA). Data were presented using descriptive statistical methods. Continuous variables were presented as mean \pm standard deviation, and categorical variables were expressed as frequency and percentages. The TLF event curve was obtained using the Kaplan-Meier method.

\section{Results}

\section{Baseline, lesion, and procedural characteristics}

The T-Flex registry analyzed a total of 1,203 patients. The mean age of the study population was $56.6 \pm 10.7$ years with male 
Table 1. Baseline characteristics for overall study patient population and high-risk subgroups implanted with ultrathin biodegradable polymer-coated sirolimus-eluting stents

\begin{tabular}{|c|c|c|c|c|c|}
\hline Characteristics & $\begin{array}{l}\text { Total patients } \\
\qquad(n=1,203)\end{array}$ & $\begin{array}{l}\text { Diabetes mellitus } \\
\qquad(\mathrm{n}=387)\end{array}$ & $\begin{array}{c}\text { Small vessel } \\
(\leq 2.5 \mathrm{~mm})(\mathrm{n}=374)\end{array}$ & $\begin{array}{l}\text { Total occlusion } \\
\quad(\mathrm{n}=208)\end{array}$ & $\begin{array}{c}\text { ST-elevation } \\
\text { myocardial infarction } \\
(\mathrm{n}=291)\end{array}$ \\
\hline Age (years), mean $\pm S D$ & $56.6 \pm 10.7$ & $55.74 \pm 9.88$ & $58.30 \pm 9.75$ & $57.38 \pm 10.25$ & $55.42 \pm 11.62$ \\
\hline Male, $n(\%)$ & $884(73.5)$ & $268(69.3)$ & $249(66.6)$ & $143(68.8)$ & $225(77.3)$ \\
\hline \multicolumn{6}{|l|}{ Cardiovascular risk } \\
\hline Diabetes mellitus, $\mathrm{n}(\%)$ & $387(32.2)$ & $387(100.0)$ & $141(37.7)$ & $61(29.3)$ & $85(29.2)$ \\
\hline Smoking, $\mathrm{n}(\%)$ & $236(19.6)$ & $56(14.5)$ & $59(15.8)$ & $37(17.8)$ & $78(26.8)$ \\
\hline $\begin{array}{l}\text { Family history of coronary artery } \\
\text { disease, } \mathrm{n}(\%)\end{array}$ & $38(3.2)$ & $18(4.7)$ & $16(4.3)$ & $12(5.8)$ & $9(3.1)$ \\
\hline Previous stroke, n (\%) & $26(2.2)$ & $14(3.6)$ & $6(1.6)$ & $2(1.0)$ & $7(2.4)$ \\
\hline Renal insufficiency, n (\%) & $14(1.2)$ & $5(1.3)$ & $6(1.6)$ & $2(1.0)$ & $4(1.4)$ \\
\hline Cardiogenic shock, n (\%) & $33(2.7)$ & $8(2.1)$ & $9(2.4)$ & $4(1.9)$ & $0(0.0)$ \\
\hline \multicolumn{6}{|l|}{ Clinical presentation } \\
\hline Stable angina, $\mathrm{n}(\%)$ & $312(25.9)$ & $117(30.2)$ & $91(24.3)$ & $47(22.6)$ & - \\
\hline Unstable angina, $\mathrm{n}(\%)$ & $432(35.9)$ & $145(37.5)$ & $144(38.5)$ & $83(39.9)$ & - \\
\hline $\begin{array}{l}\text { ST-elevation myocardial infarction, } \\
\mathrm{n}(\%)\end{array}$ & $291(24.2)$ & 84 27.7) & $80(21.4)$ & $53(25.5)$ & $291(100.0)$ \\
\hline
\end{tabular}

preponderance $(\mathrm{n}=884 ; 73.5 \%)$. Consistent with a real-world allcomer and high-risk patient population, 516 (42.9\%), 402 (33.4\%), 387 (32.2\%), 106 (8.8\%), and 596 (49.5\%) patients had hypertension, hypercholesterolemia, diabetes mellitus, history of revascularization, and multi-vessel coronary artery disease, respectively. A total of 1,624 SES (1.4 \pm 0.5 stent/patient) were implanted to treat 1,430 coronary lesions $(1.1 \pm 0.4$ stent/lesion). Of these lesions, 1,194 (83.5\%) were complex (i.e. type B2/C) and 208 $(17.3 \%)$ were total occlusions. Of the 208 occlusions observed, $67(32.2 \%)$ were chronic total occlusions. The mean length and diameter of implanted SES were $26.0 \pm 8.8 \mathrm{~mm}$ and $2.9 \pm 0.3 \mathrm{~mm}$, respectively. Device success was achieved in 1,417 (99.1\%) lesions, and procedural success was achieved in 1,194 (99.3\%) patients. There was no stent fracture observed during the procedure. One case of dissection during post-dilatation and no cases of rupture during pre- and post-dilatation were recorded. At hospital discharge, 1,181 (98.2\%) patients adhered to aspirin, whereas $1,165(96.8 \%)$ patients adhered to DAPT. Clopidogrel followed by ticagrelor and prasugrel were the most common
P2Y 12 inhibitors adhered to by 703 (59.0\%), 347 (29.1\%), and 131 $(11.0 \%)$ patients, respectively. The baseline characteristics for the overall study population and the high-risk subgroups are detailed in Table 1. The lesion and procedural details for the overall study population are outlined in Table 2.

\section{Clinical outcomes}

The one-year follow-up data were obtained for 1,143 (95.0\%) patients. The primary endpoint of TLF at one year was 3.8\% [95\% confidence interval (Cl) $2.9-5.1]$, composed of $0.6 \%(95 \% \mathrm{Cl}$ : $0.3-1.3)$ cardiac death, $1.3 \%(95 \% \mathrm{Cl}: 0.8-2.2) \mathrm{TV}-\mathrm{MI}$, and $1.9 \%$ (95\% Cl: 1.3-2.9) CI-TLR. In the high-risk subgroups, TLF at one year was $6.8 \%(95 \% \mathrm{Cl}: 4.6-9.8)$ in the diabetes mellitus, $5.2 \%$ (95\% Cl: 3.4-8) in the small-vessel disease, 6.1\% (95\% Cl: 3.9-9.6) in the STEMI, and $4.5 \%(95 \% \mathrm{Cl}: 2.4-8.3)$ in total occlusion subgroups. The additional safety endpoint, stent thrombosis, occurred in nine $(0.8 \%)$ patients in the overall population comprising of three $(0.3 \%)$, four $(0.3 \%)$, and two $(0.2 \%)$ patients with definite, probable, and possible stent thrombosis, respectively. 


\begin{tabular}{|c|c|}
\hline Characteristics & $\begin{array}{l}\text { Patients } \\
(n=1,203)\end{array}$ \\
\hline \multicolumn{2}{|l|}{ Disease vessel (1,203 patients) } \\
\hline Single-vessel disease, $\mathrm{n}(\%)$ & $607(50.5)$ \\
\hline Double-vessel disease, $\mathrm{n}(\%)$ & $479(39.8)$ \\
\hline Triple-vessel disease, $\mathrm{n}(\%)$ & $117(9.7)$ \\
\hline \multicolumn{2}{|l|}{ Target coronary artery (1,430 lesions) } \\
\hline Left anterior descending artery, $\mathrm{n}(\%)$ & $721(50.4)$ \\
\hline Right coronary artery, $\mathrm{n}(\%)$ & $431(30.1)$ \\
\hline Left circumflex artery, $\mathrm{n}(\%)$ & $270(18.9)$ \\
\hline Left main, $\mathrm{n}(\%)$ & $4(0.3)$ \\
\hline Saphenous vein graft, $\mathrm{n}(\%)$ & $4(0.3)$ \\
\hline \multicolumn{2}{|l|}{ Lesion details (1,430 lesions) } \\
\hline Type A*, n (\%) & $74(5.2)$ \\
\hline Type B1* ${ }^{*}$ (\%) & $162(11.3)$ \\
\hline Type B2* ${ }^{*}$ (\%) & $201(14.1)$ \\
\hline Type C*, n (\%) & $993(69.4)$ \\
\hline Total occlusion, n (\%) & $208(17.3)$ \\
\hline Pre-dilatation, $\mathrm{n}(\%)$ & $1,074(89.3)$ \\
\hline Maximum balloon length, mm (mean \pm SD) & $16.8 \pm 3.8$ \\
\hline Maximum balloon diameter, $\mathrm{mm}$ (mean $\pm \mathrm{SD}$ ) & $2.7 \pm 0.60$ \\
\hline Post-dilatation, n (\%) & $991(82.4)$ \\
\hline Device success, n (\%) & $1,417(99.1)$ \\
\hline Procedural success, n (\%) & 1,194 (99.3) \\
\hline \multicolumn{2}{|l|}{ Stent details (1,624 stents) } \\
\hline No. of stents deployed per patient, (mean \pm SD) & $1.4 \pm 0.5$ \\
\hline No. of stents deployed per lesion, (mean \pm SD) & $1.1 \pm 0.4$ \\
\hline Stent length, mm (mean \pm SD) & $26.0 \pm 8.8$ \\
\hline Stent diameter, mm (mean \pm SD) & $2.9 \pm 0.3$ \\
\hline \multicolumn{2}{|l|}{ Dual antiplatelet therapy } \\
\hline \multicolumn{2}{|l|}{ At hospital discharge (1,203 patients) } \\
\hline Aspirin, $\mathrm{n}(\%)$ & $1,181(98.2)$ \\
\hline$P 2 Y_{12}$ inhibitors, $\mathrm{n}(\%)$ & $1,192(99.1)$ \\
\hline Clopidogrel, n (\%) & $703(59.0)$ \\
\hline Ticagrelor, n (\%) & $347(29.1)$ \\
\hline Prasugrel, n (\%) & $131(11.0)$ \\
\hline Aspirin $+\mathrm{P}_{2} \mathrm{Y}_{12}$ inhibitors, $\mathrm{n}(\%)$ & $1,165(96.8)$ \\
\hline \multicolumn{2}{|l|}{ At 1-year (1,143 patients) } \\
\hline Aspirin, $\mathrm{n}(\%)$ & $1,039(87.2)$ \\
\hline $\mathrm{P} 2 \mathrm{Y}_{12}$ inhibitors, $\mathrm{n}(\%)$ & $1,087(91.2)$ \\
\hline Clopidogrel, n (\%) & $641(56.1)$ \\
\hline Ticagrelor, n (\%) & $291(25.5)$ \\
\hline Prasugrel, n (\%) & $109(9.5)$ \\
\hline Aspirin + $\mathrm{P}_{2} \mathrm{Y}_{12}$ inhibitors, $\mathrm{n}(\%)$ & $1,023(85.8)$ \\
\hline \multicolumn{2}{|c|}{$\begin{array}{l}\text { *According to American College of Cardiology (ACC)/American Heart Association (AHA } \\
\text { lesion morphology criteria. } \\
\text { Data presented as percentages ( } 95 \% \text { confidence interval). } \\
\text { SD - standard deviation }\end{array}$} \\
\hline
\end{tabular}

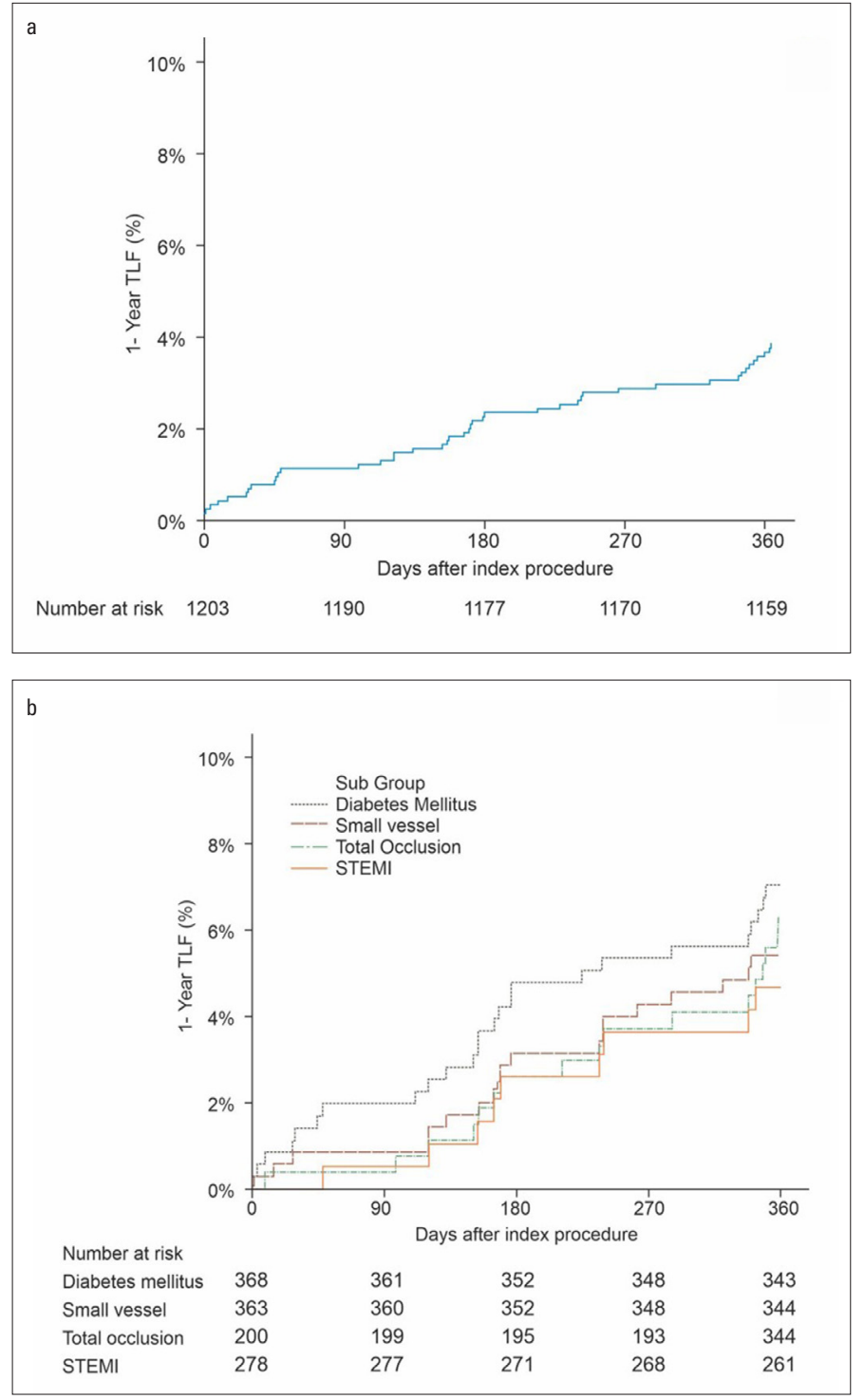

Figure 3. Kaplan-Meier event curve for cumulative target lesion failure during one-year follow-up for (a) overall patients and (b) high-risk subgroup

At one-year follow-up, 1,039 (87.2\%) patients adhered to aspirin, and $1,023(85.8 \%)$ patients adhered to DAPT. The trend of clopidogrel followed by ticagrelor and prasugrel being the most common $\mathrm{P}_{2} \mathrm{Y}_{12}$ inhibitors remained as at hospital discharge. The clinical outcomes at one year are demonstrated in Table 3. Cumulative TLF-free survival for the overall study population and high-risk subgroups at the one-year follow-up determined by the Kaplan-Meier method are illustrated in Figures $3 a$ and $3 b$, respectively.

\section{Discussion}

The T-Flex registry reported $3.8 \%$ one-year TLF for the overall study population. This outcome is acceptable when compared with 2.8-5.1\% TLF rates in the BIOFLOW-III Canada Registry (26), S-FLEX UK Registry (27), BIOFLOW-III Italian Satellite Registry (28), ULISSE Registry (29), and the BIOFLOW- 


\begin{tabular}{|c|c|c|c|c|c|}
\hline & \multicolumn{5}{|c|}{ At 1-year follow-up } \\
\hline & $\begin{array}{c}\text { Total patients } \\
(n=1,203)\end{array}$ & $\begin{array}{c}\text { Diabetes mellitus } \\
\qquad(n=387)\end{array}$ & $\begin{array}{c}\text { Small vessel } \\
(\leq 2.5 \mathrm{~mm})(\mathrm{n}=374)\end{array}$ & $\begin{array}{l}\text { Total occlusion } \\
\text { ( } \mathrm{n}=\mathbf{2 0 8 )}\end{array}$ & $\begin{array}{c}\text { ST-elevation } \\
\text { myocardial infarction } \\
(\mathrm{n}=291)\end{array}$ \\
\hline No. of patients at follow-up, $\mathrm{n}(\%)$ & $1,143(95.0)$ & $368(95.1)$ & $363(97.1)$ & $200(96.2)$ & $278(95.5)$ \\
\hline No. of patients lost to follow-up, $n$ & 60 & 19 & 11 & 8 & 13 \\
\hline Cardiac death, $(\%)$ & $0.6(0.3-1.3)$ & $0.5(0.1-2.0)$ & $0.6(0.2-2)$ & $1.0(0.3-3.6)$ & $1.1(0.4-3.1)$ \\
\hline Non-cardiac death, (\%) & $0.5(0.2-1.1)$ & $0.8(0.0-2.4)$ & $0.8(0.3-2.4)$ & $0.5(0.1-2.8)$ & $0.4(0.1-2.0)$ \\
\hline All myocardial infarction, $(\%)$ & $2.1(1.4-3.1)$ & $2.4(1.3-4.6)$ & $5.2(3.4-8.0)$ & $4.0(2.0-7.7)$ & $4.7(2.8-7.8)$ \\
\hline TV-MI, (\%) & $1.3(0.8-2.2)$ & $2.4(1.3-4.6)$ & $2.5(1.3-4.6)$ & $1.5(0.5-4.3)$ & $2.2(1.0-4.6)$ \\
\hline
\end{tabular}

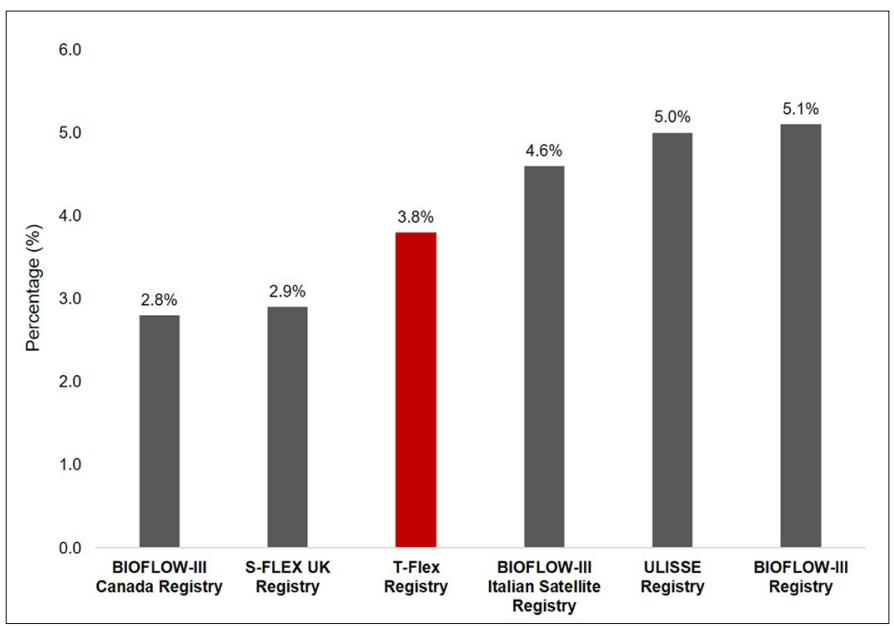

Figure 4. One-year target lesion failure rates of contemporary biodegradable polymer-coated ultrathin and very thin sirolimus-eluting stents

III Registry (16). The comparison of one-year TLF among these registries is displayed in Figure 4. All these studies were prospective multicenter registries assessing the safety and performance of very thin and ultrathin biodegradable polymer SES in all-comer populations.

Meta-analyses including earlier, first, and second-generation DES have proven limus-eluting drugs, more specifically SES, to be superior to other DES in terms of safety and clinical performance $(30,31)$. However, the diabetic population reveals the "Achilles' heel" of DES. Thus, as anticipated, the primary endpoint of one-year TLF was $6.8 \%$ in the T-Flex registry diabetic subgroup. This finding is similar to those of other studies assessing safety and clinical performance in a diabetic population implanted with limus-eluting stents that reported $6.7 \%$ (32), $6.9 \%$ (28), 7.8\% (33), and 7.8\% (34) one-year TLF rates as shown in Figure 5a. The SUGAR trial (35) is the first randomized head-to- head trial comparing second-generation DES in an all-comer diabetic population. The outcomes of this trial are expected to weigh in on the discussion regarding the treatment of the spectrum of diabetic patients with coronary artery disease.

Small-vessel coronary artery disease has been synonymous with restenosis, thrombosis, and other adverse events in the past. However, improved outcomes in this patient subgroup are not attributable to modifications in drug, drug release kinetics, polymers, metal alloys, or coating biocompatibility but rather to strut thickness. Thick strut cross-sections protrude further into the arterial lumen contributing more significantly to stentinduced luminal obstruction as opposed to thin strut cross-sections. The proven benefit of ultrathin new-generation DES becomes more pronounced in small coronary arteries in which thicker struts and smaller minimum in-stent lumen diameter serve as surrogates of in-stent restenosis. Clinical evidence of the aforementioned observation has been validated by the smallvessel subgroup of the BIO-RESORT trial (36), which compared ultrathin $(60 \mu \mathrm{m})$, very thin $(74 \mu \mathrm{m})$, and thin $(91 \mu \mathrm{m})$ strut stents. The primary endpoint of one-year TLF occurred in $4.0 \%, 4.3 \%$, and $5.0 \%$ patients, respectively. The T-Flex Registry one-year TLF rate was $5.2 \%$ in the small vessel $(\leq 2.5 \mathrm{~mm})$ subgroup. However, the higher prevalence of small coronary artery disease among women and diabetics should be taken into account (36). The T-Flex registry small-vessel subgroup comprised $33.4 \%$ women and $37.7 \%$ diabetics, whereas the BIO-RESORT small-vessel subgroup implanted with an ultrathin SES comprised $30.1 \%$ women and $19.2 \%$ diabetics. Furthermore, in the context of other studies on ultrathin and thin DES, the one-year TLF rate of the present registry compares well with the CENTURY II trial (37) and RESOLUTE ONYX $2.0 \mathrm{~mm}$ Clinical Study (38), which reported $6.9 \%$ and $5.0 \%$ 1-year TLF, respectively, as illustrated in Figure $5 \mathrm{~b}$.

Patients with STEMI are most prone to suffer early and late adverse events post percutaneous coronary intervention. 


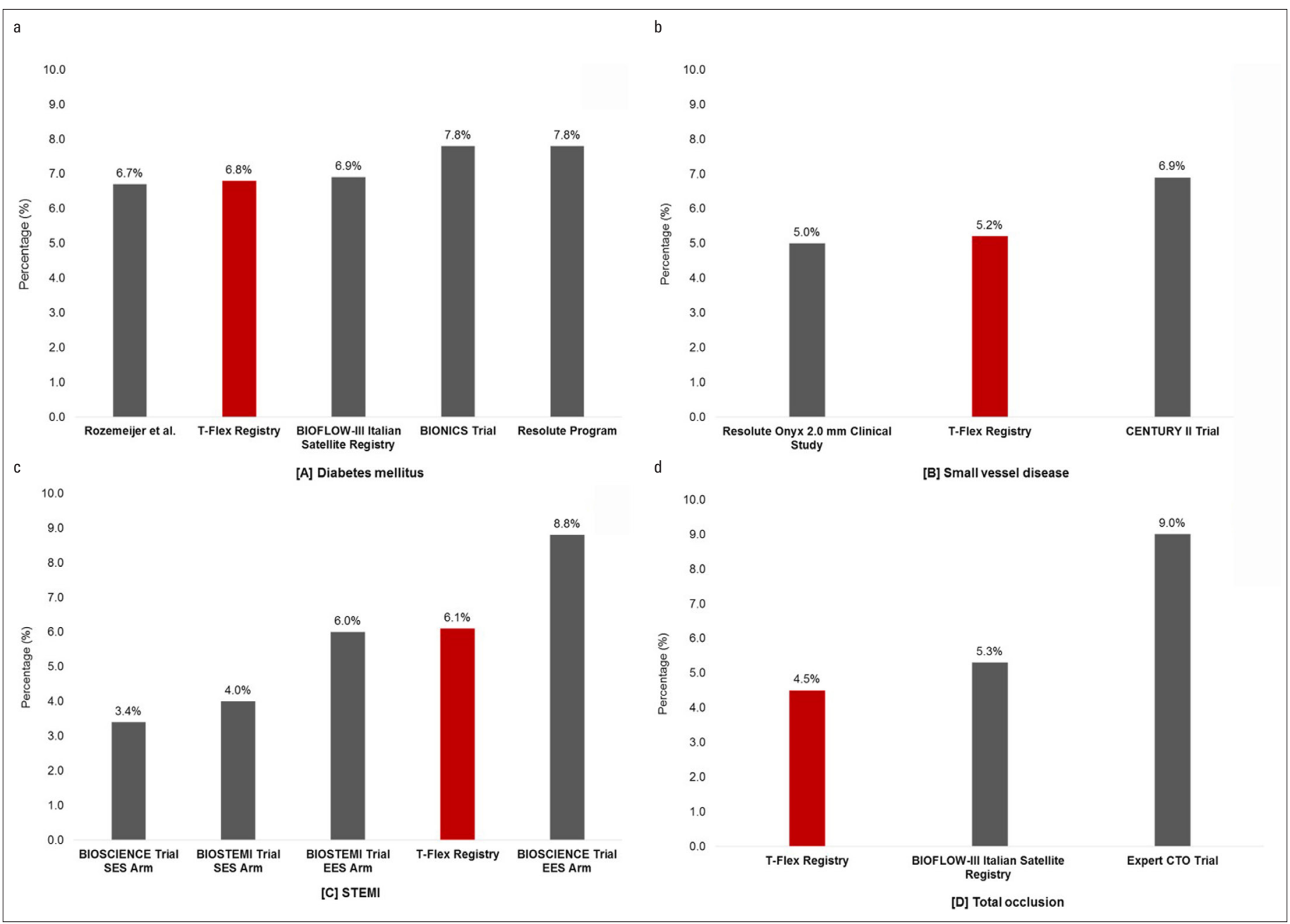

Figure 5. Comparison of one-year target lesion failure rates in high-risk subgroups in the present registry and other registries and trials for (a) diabetes mellitus; (b) small-vessel disease; (c) ST-segment elevation myocardial infarction; and (d) total occlusions

A triad of vulnerable plaque, heightened thrombotic burden and recurrent episodes of inflammation predispose these patients to delayed vascular healing with positive remodeling consequencing sequelae such as stent thrombosis and other cardiac events (39). After a decade of the plethora of head-to-head non-inferiority trials assessing stents differing in polymer, strut thickness, and drug in all-comer populations (17, 40-42), further insights specifically for patients with STEMI have been provided by the BIOSTEMI trial. This landmark trial (43) was the first head-tohead randomized controlled trial powered for superiority comparing an ultrathin biodegradable polymer SES over a thin durable polymer everolimus-eluting stent (EES) in a STEMI population. The primary endpoint of one-year TLF occurred in $4.0 \%$ in the biodegradable polymer SES arm and $6.0 \%$ in the durable polymer EES arm. Similarly, one-year TLF occurred in $3.4 \%$ in the biodegradable polymer SES arm and $8.8 \%$ in the durable polymer EES arm in the BIOSCIENCE STEMI subgroup (44) as indicated in Figure $5 \mathrm{c}$. The current registry reported a one-year TLF of $6.1 \%$ in the STEMI subgroup. Although this finding is comparable to the other trials, it is higher than that of other high-risk groups and represents an arena that warrants further research.
The early era of percutaneous coronary intervention depicted a grim picture of chronic total occlusions. Labeled the most challenging lesion subset, these lesions had been plagued by lower procedural success rates, higher rates of procedural complications, and restenosis compared with non-occlusive lesions. However, advances in guidewires, devices, procedural approaches, and skilled operators have paved the way to higher procedural success rates and favorable clinical outcomes (45). Recently, the ERCTO Registry (45) and J-CTO Registry (46) reported $82.9 \%$ and $86.6 \%$ procedural success, respectively. Furthermore, the T-Flex Registry, BIOFLOW-III Italian Satellite Registry (28), and EXPERT CTO trial (47) reported $4.5 \%, 5.3 \%$, and $9.1 \%$ one-year TLF rates in patients with total occlusion, respectively, as demonstrated in Figure 5d. Although these findings are encouraging, older age and more comorbidities in this patient subset should be taken into consideration (48). The T-Flex registry total occlusion subgroup reflects this observation comprising $47.1 \%$ patients with hypertension, $38.0 \%$ with hypercholesteremia, $29.3 \%$ with diabetes, and $11.0 \%$ with previous revascularization. In addition, the vast spectrum of influential factors determining the clinical outcomes in these patients should be acknowledged. 
Overall, the results with the ultrathin SES in this T-Flex registry are consistent with those observed in previous studies on biodegradable polymer-coated as well as durable polymer DES. Further follow-up is intended to assess the long-term safety and clinical performance with the ultrathin SES.

\section{Study limitations}

The major limitation of this registry was the retrospective, single-arm, and observational study design. All the patients were not followed up through clinic visits; and thus, some clinicallyindicated revascularizations might have been missed. Another limitation was the lack of head-to-head comparison with other latest-generation stents, which could have provided better insights into the outcomes. Further, the results of this registry cannot be directly compared with the results from any other registry or trial. Different DES may have different drug load, biodegradable polymer composition, polymer coating, and release kinetics, which may all ultimately influence the final DES performance. Nevertheless, our results are consistent with other studies.

\section{Conclusion}

The low event rates of one-year TLF and stent thrombosis clearly depict excellent safety and clinical performance of this ultrathin biodegradable polymer-coated SES in real-world allcomer populations as well as in high-risk subgroups with coronary artery disease. Future studies with comparative analysis and long-term follow-up are warranted.

\section{Conflict of interest: None declared.}

Peer-review: Externally peer-reviewed.

Author contributions: Concept - R.B.P., V.V., A.Potdar, M.K.I., A. Pathak, S.S.M., P.A.; Design - R.B.P., V.V., A.Potdar, M.K.I., A.Pathak, S.S.M., P.A.; Supervision - R.B.P., V.V., A.Potdar, M.K.I., A.Pathak, S.S.M., P.A.; Fundings - R.B.P., V.V., A.Potdar, M.K.I., A.Pathak, S.S.M., P.A.; Materials - R.B.P., V.V., A.Potdar, M.K.I., A.Pathak, S.S.M., P.A.; Data collection \&/or processing - R.B.P., V.V., A.Potdar, M.K.I., A.Pathak, S.S.M., P.A.; Analysis \&/or interpretation - R.B.P., V.V., A.Potdar, M.K.I., A.Pathak, S.S.M., P.A.; Literature search - R.B.P.; Writing - R.B.P.; Critical review R.B.P., V.V., A.Potdar, M.K.I., A.Pathak, S.S.M., P.A.

\section{References}

1. McFadden EP, Stabile E, Regar E, Cheneau E, Ong AT, Kinnaird T, et al. Late thrombosis in drug-eluting coronary stents after discontinuation of antiplatelet therapy. Lancet 2004; 364: 1519-21. [Crossref]

2. Lagerqvist B, Carlsson J, Fröbert 0, Lindbäck J, Scherstén F, Stenestrand U, et al.; Swedish Coronary Angiography and Angioplasty Registry Study Group. Stent thrombosis in Sweden: a report from the Swedish Coronary Angiography and Angioplasty Registry. Circ Cardiovasc Interv 2009; 2: 401-8. [Crossref]

3. Joner M, Finn AV, Farb A, Mont EK, Kolodgie FD, Ladich E, et al. Pathology of drug-eluting stents in humans: Delayed healing and late thrombotic risk. J Am Coll Cardiol 2006; 48: 193-202. [Crossref]
4. Kalra A, Rehman H, Khera S, Thyagarajan B, Bhatt DL, Kleiman NS, et al. New-Generation Coronary Stents: Current Data and Future Directions. Curr Atheroscler Rep 2017; 19: 14. [Crossref]

5. Simard T, Hibbert B, Ramirez FD, Froeschl M, Chen YX, O'Brien ER. The evolution of coronary stents: A brief review. Can $\mathrm{J}$ Cardiol 2014; 30: 35-45. [Crossref]

6. Ho MY, Chen CC, Wang CY, Chang SH, Hsieh MJ, Lee CH, et al. The development of coronary artery stents: From bare-metal to bioresorbable types. Metals 2016; 6: 168. [Crossref]

7. Foerst J, Vorpahl M, Engelhardt M, Koehler T, Tiroch K, Wessely R. Evolution of coronary stents: From bare-metal stents to fully biodegradable, drug-eluting stents. Combination Products in Therapy 2013; 3: 9-24. [Crossref]

8. John MC, Wessely R, Kastrati A, Schömig A, Joner M, Uchihashi M, et al. Differential healing responses in polymer-and nonpolymerbased sirolimus-eluting stents. JACC Cardiovasc Interv 2008; 1: 535-44. [Crossref]

9. Puranik AS, Dawson ER, Peppas NA. Recent advances in drug eluting stents. Int J Pharm 2013; 441: 665-79. [Crossref]

10. Kastrati A, Mehilli J, Dirschinger J, Dotzer F, Schuhlen H, Neumann FJ, et al. Intracoronary Stenting and Angiographic Results Strut Thickness Effect on Restenosis Outcome (ISAR-STEREO) Trial. Vestn Rentgenol Radiol 2012; 2: 52-60. [Article in Russian]

11. Pache J, Kastrati A, Mehilli J, Schühlen H, Dotzer F, Hausleiter J, et al. Intracoronary stenting and angiographic results: strut thickness effect on restenosis outcome (ISAR-STEREO-2) trial. J Am Coll Cardiol 2003; 41: 1283-8. [Crossref]

12. Lemos PA, Chandwani $P$, Saxena $S$, Ramachandran PK, Abhyankar A, Campos CM, et al. Clinical outcomes in 995 unselected realworld patients treated with an ultrathin biodegradable polymercoated sirolimus-eluting stent: 12-month results from the FLEX Registry. BMJ Open 2016; 6: e010028. [Crossref]

13. Shetty R, Prajapati J, Pai U, Shetty K. Preliminary Evaluation of Clinical and Angiographic Outcomes with Biodegradable Polymer Coated Sirolimus-Eluting Stent in De Novo Coronary Artery Disease: Results of the MANIPAL-FLEX Study. Scientifica (Cairo) 2016; 2016: 9324279. [Crossref]

14. Hamon M, Niculescu R, Deleanu D, Dorobantu M, Weissman NJ, Waksman R. Clinical and angiographic experience with a thirdgeneration drug-eluting Orsiro stent in the treatment of single de novo coronary artery lesions (BIOFLOW-I): a prospective, first-inman study. Eurolntervention 2013; 8: 1006-11. [Crossref]

15. Windecker S, Haude M, Neumann FJ, Stangl K, Witzenbichler B, Slagboom T, et al. Comparison of a novel biodegradable polymer sirolimus-eluting stent with a durable polymer everolimus-eluting stent: results of the randomized BIOFLOW-II trial. Circ Cardiovasc Interv 2015; 8: e001441. [Crossref]

16. Waltenberger J, Brachmann J, van der Heyden J, Richardt G, Fröbert 0, Seige M, et al.; BIOFLOW-III Investigators. Real-world experience with a novel biodegradable polymer sirolimus-eluting stent: twelve-month results of the BIOFLOW-III registry. Eurolntervention 2016; 11: 1106-10. [Crossref]

17. Kandzari DE, Mauri L, Koolen JJ, Massaro JM, Doros G, GarciaGarcia HM, et al.; BIOFLOW V Investigators. Ultrathin, bioresorbable polymer sirolimus-eluting stents versus thin, durable polymer everolimus-eluting stents in patients undergoing coronary revascularisation (BIOFLOW V): a randomised trial. Lancet 2017; 390: 1843-52. [Crossref]

18. Pilgrim T, Heg D, Roffi M, Tüller D, Muller O, Vuilliomenet A, et al. Ultrathin strut biodegradable polymer sirolimus-eluting stent ver- 
sus durable polymer everolimus-eluting stent for percutaneous coronary revascularisation (BIOSCIENCE): a randomised, singleblind, non-inferiority trial. Lancet 2014; 384: 2111-22. [Crossref]

19. von Birgelen C, Kok MM, van der Heijden LC, Danse PW, Schotborgh $\mathrm{CE}$, Scholte $\mathrm{M}$, et al. Very thin strut biodegradable polymer everolimus-eluting and sirolimus-eluting stents versus durable polymer zotarolimus-eluting stents in allcomers with coronary artery disease (BIO-RESORT): a three-arm, randomised, non-inferiority trial. Lancet 2016; 388: 2607-17. [Crossref]

20. Jensen LO, Thayssen P, Maeng M, Ravkilde J, Krusell LR, Raungaard $B$, et al. Randomized comparison of a biodegradable polymer ultrathin strut sirolimus-eluting stent with a biodegradable polymer biolimus-eluting stent in patients treated with percutaneous coronary intervention: the SORT OUT VII trial. Circ Cardiovasc Interv 2016; 9: e003610. [Crossref]

21. Xu B, Gao RL, Zhang RY, Wang HC, Li ZO, Yang YJ, et al. Efficacy and safety of FIREHAWK® abluminal groove filled biodegradable polymer sirolimus-eluting stents for the treatment of long coronary lesions: nine-month angiographic and one-year clinical results from TARGET I trial long cohort. Chin Med J (Engl) 2013; 126: 1026-32.

22. Dixon JR Jr. The International Conference on Harmonization Good Clinical Practice guideline. Qual Assur 1998; 6: 65-74. [Crossref]

23. General Assembly of the World Medical Association. World Medical Association Declaration of Helsinki: ethical principles for medical research involving human subjects. J Am Coll Dent 2014; 81: 14-8.

24. Cutlip DE, Windecker S, Mehran R, Boam A, Cohen DJ, van Es GA, et al.; Academic Research Consortium. Clinical end points in coronary stent trials: a case for standardized definitions. Circulation 2007; 115: 2344-51. [Crossref]

25. Thygesen K, Alpert JS, Jaffe AS, Simoons ML, Chaitman BR, White HD; Joint ESC/ACCF/AHA/WHF Task Force for Universal Definition of Myocardial Infarction; Authors/Task Force Members Chairpersons. Third universal definition of myocardial infarction. $J$ Am Coll Cardiol 2012; 60: 1581-98. [Crossref]

26. Boukhris M, Potter BJ, Fam NP, Matteau A, Graham JJ, Gobeil F, et al. Safety and Performance of the Orsiro Sirolimus-Eluting Stent in the Treatment of All-Comers Patient Population in Daily Clinical Practice. Cardiovasc Revasc Med 2020; 21: 1348-54. [Crossref]

27. Choudhury A, Garg S, Smith J, Sharp A, Nabais de Araujo S, Chauhan $A$, et al. Prospective evaluation of an ultrathin strut biodegradable polymer-coated sirolimus-eluting stent: 12 months' results from the S-FLEX UK registry. BMJ Open 2019; 9: e026578. [Crossref]

28. Bartorelli AL, Versaci F, Briguori C, Tomai F, Aprigliano G, Poli A, et al. The BIOFLOW-III Italian Satellite Registry: 18-month results of the Orsiro stent in an all-comer high-risk population. J Cardiovasc Med (Hagerstown) 2019; 20: 464-70. [Crossref]

29. Godino C, Beneduce A, Ferrante G, Ielasi A, Pivato CA, Chiarito M, et al. One-year clinical outcome of biodegradable polymer sirolimus-eluting stent in all-comers population. Insight from the ULISSE registry (ULtimaster Italian multicenter all comerS Stent rEgistry). Int J Cardiol 2018; 260: 36-41. [Crossref]

30. Dangas GD, Serruys PW, Kereiakes DJ, Hermiller J, Rizvi A, Newman W, et al. Meta-analysis of everolimus-eluting versus paclitaxel-eluting stents in coronary artery disease: final 3-year results of the SPIRIT clinical trials program (Clinical Evaluation of the Xience V Everolimus Eluting Coronary Stent System in the Treatment of Patients With De Novo Native Coronary Artery Lesions). JACC Cardiovasc Interv 2013; 6: 914-22. [Crossref]
31. Schömig A, Dibra A, Windecker S, Mehilli J, de Lezo JS, Kaiser C, et al. A meta-analysis of 16 randomized trials of sirolimus-eluting stents versus paclitaxel-eluting stents in patients with coronary artery disease. J Am Coll Cardiol 2007; 50: 1373-80. [Crossref]

32. Rozemeijer R, Benedetto D, Kraaijeveld A0, Voskuil M, Stein M, Timmers $L$, et al. Clinical outcomes of complex real-world diabetic patients treated with amphilimus sirolimus-eluting stents or zotarolimus-eluting stents: A single-center registry. Cardiovasc Revasc Med 2018; 19: 521-5. [Crossref]

33. Konigstein M, Ben-Yehuda O, Smits PC, Love MP, Banai S, Perlman GY, et al. Outcomes Among Diabetic Patients Undergoing Percutaneous Coronary Intervention With Contemporary DrugEluting Stents: Analysis From the BIONICS Randomized Trial. JACC Cardiovasc Interv 2018; 11: 2467-76. [Crossref]

34. Silber S, Serruys PW, Leon MB, Meredith IT, Windecker S, Neumann FJ, et al. Clinical outcome of patients with and without diabetes mellitus after percutaneous coronary intervention with the resolute zotarolimus-eluting stent: 2-year results from the prospectively pooled analysis of the international global RESOLUTE program. JACC Cardiovasc Interv 2013; 6: 357-68. [Crossref]

35. Romaguera $R$, Salinas $P$, Brugaletta $S$, Gomez-Lara J, Díaz JF, Romero MA, et al. Second-Generation Drug-Eluting Stents in Diabetes (SUGAR) trial: Rationale and study design. Am Heart $\mathrm{J}$ 2020; 222: 174-82. [Crossref]

36. Buiten RA, Ploumen EH, Zocca P, Doggen CJM, van der Heijden LC, Kok MM, et al. Outcomes in Patients Treated With Thin-Strut, Very Thin-Strut, or Ultrathin-Strut Drug-Eluting Stents in Small Coronary Vessels: A Prespecified Analysis of the Randomized BIO-RESORT Trial. JAMA Cardiol 2019; 4: 659-69. [Crossref]

37. Wöhrle J, Markovic S, Rottbauer W, Muramatsu T, Kadota K, Vázquez-González N, et al. Bioresorbable polymer sirolimus-eluting coronary stent compared with permanent polymer everolimuseluting coronary stent implantation for treatment of small vessel coronary artery disease: CENTURY II trial. Eurolntervention 2016; 12: e167-74. [Crossref]

38. Price MJ, Saito S, Shlofmitz RA, Spriggs DJ, Attubato M, McLaurin B, et al. First Report of the Resolute Onyx 2.0-mm ZotarolimusEluting Stent for the Treatment of Coronary Lesions With Very Small Reference Vessel Diameter. JACC Cardiovasc Interv 2017; 10: 1381-8. [Crossref]

39. Chichareon P, Modolo R, Collet C, Tenekecioglu E, Vink MA, Oh PC, et al. Efficacy and Safety of Stents in ST-Segment Elevation Myocardial Infarction. J Am Coll Cardiol 2019; 74: 2572-84. [Crossref]

40. Maeng M, Christiansen EH, Raungaard B, Kahlert J, Terkelsen CJ, Kristensen SD, et al.; SORT OUT VIII Investigators. EverolimusEluting Versus Biolimus-Eluting Stents With Biodegradable Polymers in Unselected Patients Undergoing Percutaneous Coronary Intervention: A Randomized Noninferiority Trial With 1-Year Follow-Up (SORT OUT VIII Trial). JACC Cardiovasc Interv 2019; 12: 624-33. [Crossref]

41. Rozemeijer $R$, Stein $M$, Voskuil $M$, van den Bor R, Frambach $P$, Pereira B, et al.; ReCre8 Study Investigators. Randomized AllComers Evaluation of a Permanent Polymer Zotarolimus-Eluting Stent Versus a Polymer-Free Amphilimus-Eluting Stent. Circulation 2019; 139: 67-77. [Crossref]

42. Zaman A, de Winter RJ, Kogame N, Chang CC, Modolo R, Spitzer E, et al.; TALENT trial investigators. Safety and efficacy of a sirolimuseluting coronary stent with ultra-thin strut for treatment of atherosclerotic lesions (TALENT): a prospective multicentre randomised controlled trial. Lancet 2019; 393: 987-97. [Crossref] 
43. Iglesias JF, Muller 0, Heg D, Roffi M, Kurz DJ, Moarof I, et al. Biodegradable polymer sirolimus-eluting stents versus durable polymer everolimus-eluting stents in patients with ST-segment elevation myocardial infarction (BIOSTEMI): a single-blind, prospective, randomised superiority trial. Lancet 2019; 394: 1243-53. [Crossref]

44. Pilgrim T, Piccolo R, Heg D, Roffi M, Tüller D, Vuilliomenet A, et al. Biodegradable polymer sirolimus-eluting stents versus durable polymer everolimus-eluting stents for primary percutaneous coronary revascularisation of acute myocardial infarction. Eurolntervention 2016; 12: e1343-54. [Crossref]

45. Galassi AR, Tomasello SD, Reifart N, Werner GS, Sianos G, Bonnier $H$, et al. In-hospital outcomes of percutaneous coronary intervention in patients with chronic total occlusion: insights from the ERCTO (European Registry of Chronic Total Occlusion) registry. Eurolntervention 2011; 7: 472-9. [Crossref]
46. Morino Y, Kimura T, Hayashi Y, Muramatsu T, Ochiai M, Noguchi Y, et al. In-hospital outcomes of contemporary percutaneous coronary intervention in patients with chronic total occlusion: Insights from the J-CTO Registry (Multicenter CTO Registry in Japan). JACC Cardiovasc Interv 2010; 3: 143-51. [Crossref]

47. Kandzari DE, Kini AS, Karmpaliotis D, Moses JW, Tummala PE, Grantham JA, et al. Safety and effectiveness of everolimus-eluting stents in chronic total coronary occlusion revascularization: Results from the EXPERT CTO multicenter trial (Evaluation of the XIENCE Coronary Stent, Performance, and Technique in Chronic Total Occlusions). JACC Cardiovasc Interv 2015; 8: 761-9. [Crossref]

48. Fefer $P$, Knudtson ML, Cheema AN, Galbraith PD, Osherov AB, Yalonetsky $S$, et al. Current perspectives on coronary chronic total occlusions: The Canadian Multicenter Chronic Total Occlusions Registry. J Am Coll Cardiol 2012; 59: 991-7. [Crossref] 